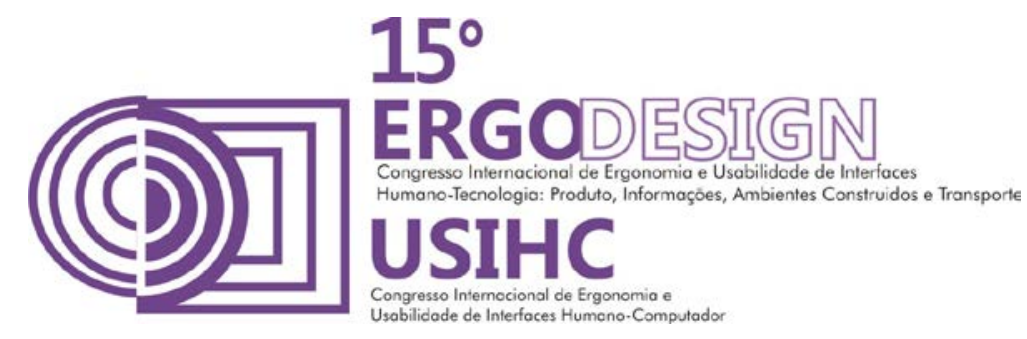

\title{
OBSERVAÇÕES ACERCA DO COMPORTAMENTO DO USUÁRIO NO TERMINAL URBANO DE JOINVILLE
}

\author{
MACHADO, Marcel (1) \\ EVERLING, Marli (2) \\ (1) Universidade da região de Joinville - Univille, Estudante de Design \\ E-mail: marcelhrmachado@gmail.com \\ (2) Univille Universidade, Doutora em Design \\ E-mail: meverling@gmail.com
}

\begin{abstract}
RESUMO
O objetivo deste artigo é apresentar aspectos relacionados a análise de comportamento das pessoas que frequentam o terminal urbano de transporte coletivo central da cidade de Joinville, SC. As técnicas utilizadas abrangem observação sistemática e assistemática; a análise considerou o agrupamento de informações por categorias considerando a afinidades. Nas considerações finais e conclusão são apresentadas possibilidades de qualificação do ambiente do terminal derivadas das análises.
\end{abstract}

\begin{abstract}
The purpose of this article is presenting aspects related to behavior analysis from people that use the central urban bus terminal in Joinville city. Technics used at this project include systematic and unsystematic observation; the analysis considered data grouping by categories considering its affinities. Presented in the final considerations and conclusions are environment qualification possibilities derived from the analysis.
\end{abstract}

\section{INTRODUÇÃO}

Este artigo relata resultados parciais da pesquisa intitulada 'Comportamento do Usuário do Transporte Coletivo no Entorno de um Terminal Urbano Central' ${ }^{1}$. O estudo objetiva compreender como ocorre a circulação e o comportamento de pedestres nas proximidades do terminal urbano central de transporte coletivo da cidade de Joinville, SC, no intuito de possibilitar futuras intervenções de Design. Esta investigação complementa os projetos de pesquisa DS4MOB

\footnotetext{
${ }^{1}$ Resultados parciais desta pesquisa foram apresentados no ' $11^{\circ}$ Congresso Brasileiro de Pesquisa e Desenvolvimento em Design' realizado em setembro/outubro de 2014. A pesquisa também originou um artigo que foi submetido ao caderno de iniciação científica da Univille.
} 


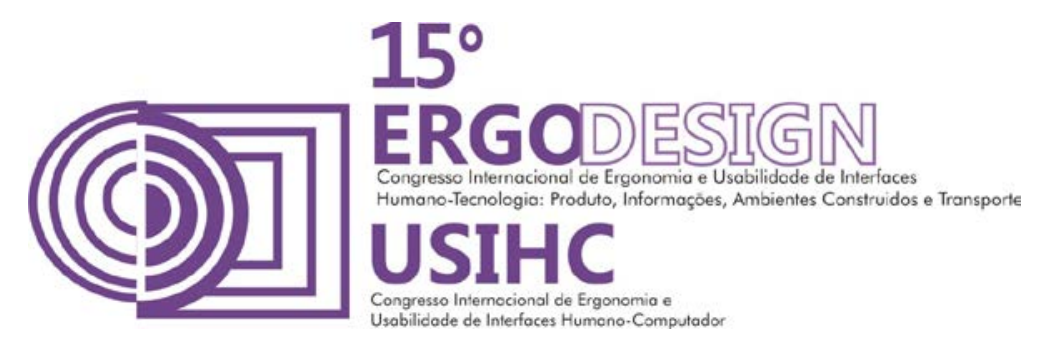

[Contribuições do design para o desenvolvimento sustentável de cidades: um estudo de caso em Joinville] e URBE [O Estudo das relações de uso e do contexto urbano como suporte ao design prospectivo de produtos e serviços na cidade de Joinville] que ancoram investigações técnicocientíficas realizadas pelos estudantes de mestrado e graduação em Design relacionados às temáticas 'desenvolvimento de produtos e serviços', 'mobilidade', 'relações de uso e contexto urbano'. O conjunto destas pesquisas originou o Laboratório de Estudos da Cidade (LECid) que conta com a participação de professores e estudantes de graduação e mestrado do de Design, entre eles, o autor deste relato.

As técnicas e procedimentos usadas para viabilizar o estudo foram: análise comparativa das técnicas de pesquisa etnográfica com as técnicas de observação clássicas de ergonomia como 'observação assistemática' e 'observação sistemática' com o intuito de delinear o percurso metodológico da pesquisa; levantamento e compartilhamento de informações sobre mobilidade urbana e usabilidade com o intuito de ampliar o repertório sobre esta temática e compreender o estado-da-arte de investigações relacionadas ao tema (esta etapa foi concretizada com a criação de um espaço virtual específico para o compartilhamento de informações); processo de coleta e análise de dados; dos dados obtidos ao longo da pesquisa, neste relato serão contemplados observações relacionados a caracterização dos usuários, ao comportamento das pessoas, ao nível de atenção no ambiente, e, informações derivadas da experiência do observador no terminal urbano central.

\section{METODOLOGIA}

Para Santa Rosa (2013) o uso de técnicas etnográficas pode contribuir com a aproximação do designer dos contextos de uso. Ele destaca a relevância de ações como 'ouvir, enxergar', 'intuir' a relação de uso no contexto real de interação com sistemas, produtos ou serviços. Dentre as várias técnicas elencadas pelo autor destacamos, para esta investigação as técnicas 'fly-on-the-wall' e 'day-in-the-life'. A caracterização destas duas técnicas, de acordo com Moggridge esta descrita na figura 01:

\begin{tabular}{|l|l|l|}
\hline & Fly-on-the-wall & Day-in-the-life \\
\hline Como & $\begin{array}{l}\text { Observe e grave o comportamento das pessoas } \\
\text { no contexto, sem interferir em suas atividades. }\end{array}$ & $\begin{array}{l}\text { Catalogue as atividades e contexto das experiências } \\
\text { dos usuários em um dia inteiro. }\end{array}$ \\
\hline Porque & $\begin{array}{l}\text { Essa técnica é útil para enxergar o que as pessoas } \\
\text { fazem no contexto real e padrões de tempo ao } \\
\text { invés de aceitar o que relatam após o fato. }\end{array}$ & $\begin{array}{l}\text { A técnica é útil para revelar aspectos não previsíveis } \\
\text { inerentes as rotinas e circunstâncias que as pessoas } \\
\text { vivenciam diariamente. }\end{array}$ \\
\hline Exemplo & $\begin{array}{l}\text { Ao acompanhar a rotina de uma sala de cirurgia, } \\
\text { designers puderam observar e compreender } \\
\text { informações requeridas pela equipe durante a a } \\
\text { operação. }\end{array}$ & $\begin{array}{l}\text { Para o design de um dispositivo de comunicação } \\
\text { portátil a equipe de design seguiu pessoas ao longo } \\
\text { do dia observando evidencias de momentos em que a } \\
\text { comunicação se fazia necessária. }\end{array}$ \\
\hline
\end{tabular}

Figura 01: comparação das técnicas 'Fly-on-the-wall' e 'Day-in-the-life' (baseado em MOOGRIDGE, 2007, P.12) 


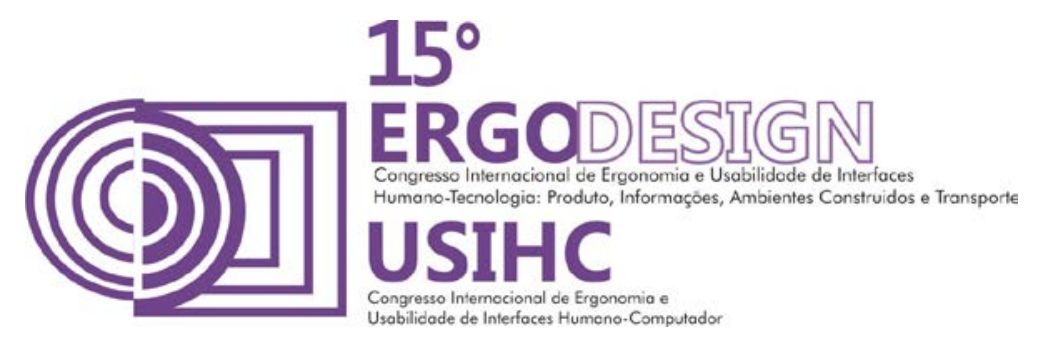

As duas técnicas apresentadas acima (e muito utilizadas no design de interação e no design participativo) possuem semelhanças com as técnicas de pesquisa mais tradicionais associadas a ergonomia, mais especificamente a 'observação assistemática' e 'observação sistemática' discutidas, entre outros métodos, por Moraes e Mont'alvão (2010) no livro 'Ergonomia, Conceitos e Aplicações'. A descrição destas técnicas está na figura 02.

\begin{tabular}{|c|c|}
\hline Observação Assistemática (ocasional/não estruturada) & Observação Sistemática (estruturada/controlada) \\
\hline $\begin{array}{l}\text { Técnica não planejada e sem critérios de controle pré- } \\
\text { definidos. }\end{array}$ & $\begin{array}{l}\text { Realizada de forma controlada visa a observação de } \\
\text { critérios definidos a priori. }\end{array}$ \\
\hline $\begin{array}{l}\text { Pode ser usada para compreender as características da } \\
\text { dinâmica de um fenômeno, ação ou interação. }\end{array}$ & $\begin{array}{l}\text { Requer planejamento de documentos e instrumentos } \\
\text { específicos (planilhas de registro, fichas de entrevista, ficha } \\
\text { de registro de comportamento, etc.). }\end{array}$ \\
\hline $\begin{array}{l}\text { observação sem que se estabeleça, a priori, aspectos a } \\
\text { serem observados ou ferramentas de apoio a observação. }\end{array}$ & $\begin{array}{l}\text { Pode contribuir com a identificação de problemas } \\
\text { relacionados a dinâmica de atividades e comportamentos. }\end{array}$ \\
\hline $\begin{array}{l}\text { A atenção do observador ao longo do processo de } \\
\text { observação é muito importante, bem como o registro das } \\
\text { informações. }\end{array}$ & $\begin{array}{l}\text { O planejamento da observação sistemática inclui a } \\
\text { delimitação: do contexto de observação, do tempo e } \\
\text { duração, da população, dos instrumentos, das }\end{array}$ \\
\hline $\begin{array}{l}\text { A fidelidade aos fatos é muito importante. Registros } \\
\text { pessoais e interpretações devem ser separados. }\end{array}$ & \\
\hline & \\
\hline
\end{tabular}

Figura 02: comparação das técnicas 'Observação Assistemática' e 'Observação Sistemática' (baseado em MORAES e MONT'ALVÃO, 2010)

Ressalta-se que apesar do reconhecimento que técnicas etnográficas como 'fly-on-the-wall' e 'dayin-the-life' são associadas à abordagens mais contemporâneas do design optamos pelo uso de nomenclaturas clássicas de ergonomia ('observação assistemática' e 'observação sistemática') pela sua consistência e pertinência aos objetivos desta pesquisa. Esta opção deriva também do entendimento que as técnicas de observação associadas ao campo da ergonômica, na essência, são muito semelhantes as citadas técnicas etnográficas.

\section{CONTEXTUALIZAÇÃO}

Thackara (2008), assim com Jaime Lerner (2007) defendem que o ônibus é o meio mais aceitável de transporte em longas distâncias. Para Lerner, considerando a realidade brasileira, este sistema é superior ao metrô devido às limitações para a construção de uma rede completa de metrô para as cidades. Mas para que o usuário opte por este serviço é necessário que o sistema que o viabiliza seja qualificado, considerando segurança, eficiência e confiabilidade. O que requer um olhar voltado para o usuário (suas prioridades, atividades e metas de locomoção). 


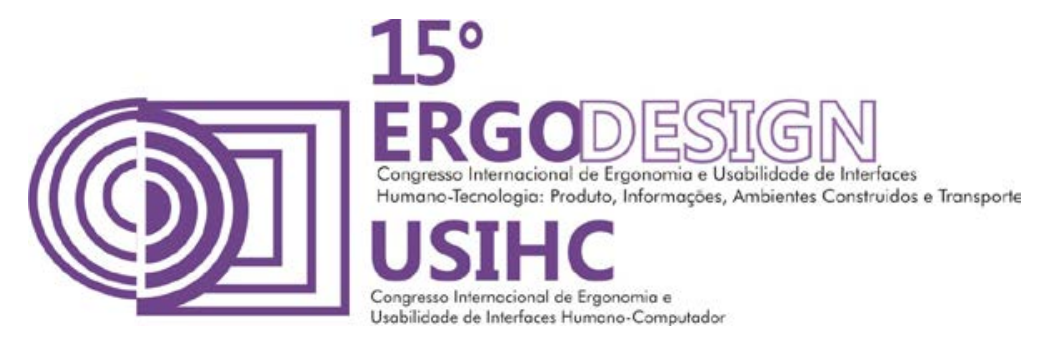

A cidade de Joinville é a maior cidade do estado de Santa Catarina e possui 494.597 habitantes. De acordo com a pesquisa intitulada Dados de Joinville (2010-2011) publicada pelo IPPUJ (Instituto de Pesquisa e Planejamento para o Desenvolvimento Sustentável de Joinville), 30,35\% dos habitantes se movem a pé e $26,8 \%$ utilizam o transporte coletivo municipal. A soma destes dados supera 0 número de pessoas que utilizam o automóvel (23,28\%). Associando o número de usuários de bicicleta $(14,6 \%)$ delineia-se um cenário que possibilita o desenvolvimento de produtos e serviços que favoreçam a integração destas três categorias de mobilidade e qualifiquem as relações do pedestre com a cidade de Joinville.

Os terminais urbanos de transporte coletivo são pontos críticos para circulação de pedestres no espaço urbano. É a partir deles que se organiza/distribui o fluxo de movimentação de pedestres.

Objeto deste estudo e o contexto estabelecido para as observações foi o terminal urbano de transporte coletivo central da cidade de Joinville (que de agora em diante será chamado terminal urbano central). Para compreender o uso deste ambiente construído e o comportamento do usuário no entorno deste espaço a figura 03 apresenta a sua caracterização do terminal urbano central.
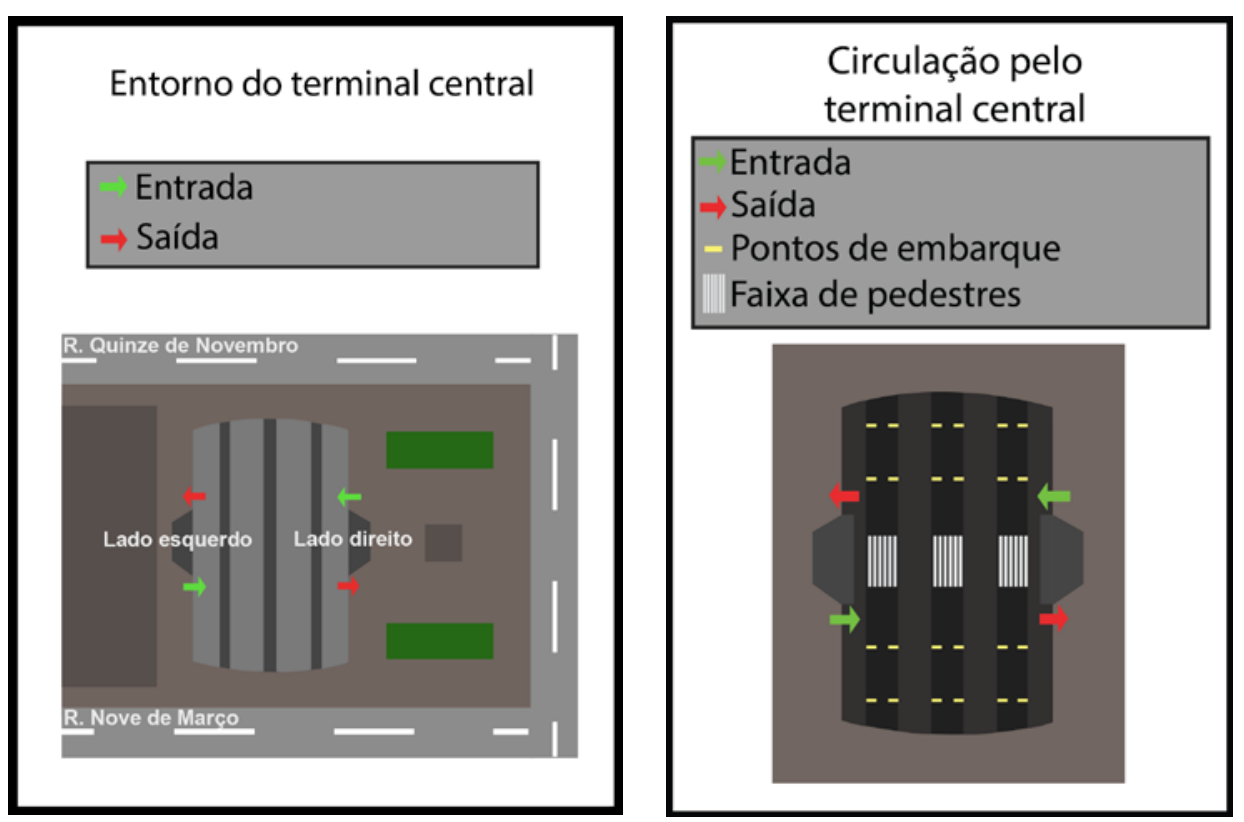

Figura 03 - Caracterização do terminal urbano central e análise do fluxo².

\footnotetext{
${ }^{2}$ Esta figura foi desenvolvida para o artigo submetido ao Caderno de Iniciação científica da Univille (Universidade da Região de Joinville).
} 


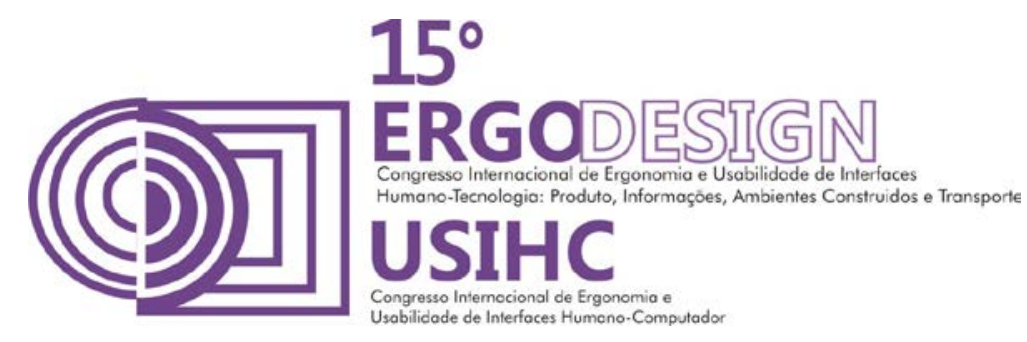

\section{OBSERVAÇÃO ASSISTEMÁTICA}

Entre os meses de fevereiro e março de 2014 foram realizadas cinco visitas ao terminal urbano central $^{3}$, como etapa exploratória da pesquisa e, no intuito de compreender a dinâmica e o contexto do espaço construído do terminal urbano central.

A partir das visitas, percebeu-se três aspectos do comportamento dos usuários no espaço relacionados as suas prioridades. O primeiro, refere-se à movimentação, que pode variar de um andar lento até uma corrida rápida. O segundo, à comunicação, que é feita pela linguagem falada, corporal, por celulares ou dispositivos semelhantes. E, por fim, o terceiro refere-se ao cuidado com os pertences e consigo mesmo. Sua relevância é variável e podem ser interdependentes; pessoas com andar lento, por exemplo, frequentemente estão utilizando o celular, ou, usuários "desobedecem" as sinalizações em prol da movimentação rápida.

A categorização das informações obtidas evidenciou alguns aspectos relevantes em relação ao uso do ambiente do terminal urbano: (1) origem do fluxo que abastece o entorno do terminal urbano central, (2) comportamento das pessoas considerando movimentação individual ou coletiva, (3) diferença de comportamento entre as pessoas que andam sozinhas e as em grupo, (4) evidências de níveis de atenção ao entorno, (5) evidências de cuidado e descuido com o lugar, (6) tipo de informações que as pessoas procuram, (7) sincronia entre fluxo de entrada e saída, (8) tempo de espera das pessoas, (9) facilidade para localizar a plataforma de embarque e (10) como as pessoas chegam ao terminal (a pé, de ônibus, de bicicleta). Esta categorização originou os critérios de análise que orientaram a observação sistemática.

\section{OBSERVAÇÃO SISTEMÁTICA}

Os critérios estabelecidos foram: (1) origem do fluxo que abastece o entorno do terminal, (2) 0 comportamento das pessoas, (3) níveis de atenção ao entorno e de cuidados com o lugar, (4) informações que as pessoas procuram, (5) sincronia entre o fluxo de entrada e saída.

A partir dos critérios foram estruturadas fichas de observação do comportamento dos usuários do terminal urbano central. O período da pesquisa se estendeu de Agosto a dezembro de 2014 totalizando nove dias de visita ao terminal ${ }^{4}$. A figura 4 apresenta a ficha que orientou as observações sistemáticas

\begin{tabular}{|l|ll|}
\hline Data: & Dia da Semana & Horário Final \\
\hline Turno & Horário inicial \\
\hline $\begin{array}{l}\text { Origem do fluxo que } \\
\text { abastece o entorno do } \\
\text { terminal urbano central: }\end{array}$ & \\
\hline Comportamento das & \\
\hline
\end{tabular}

\footnotetext{
${ }^{3}$ Estes resultados foram parcialmente apresentados no P\&D 2014 (maior evento de Design do país) sob o título Comportamento do usuário do transporte coletivo no entorno de um terminal urbano central sob a autoria de Marcel Machado .

${ }^{4}$ As 9 visitas foram divididas em 3 horários diferentes (ao amanhecer, ao meio dia e ao entardecer); para cada horário foram realizadas 3 visitas.
} 


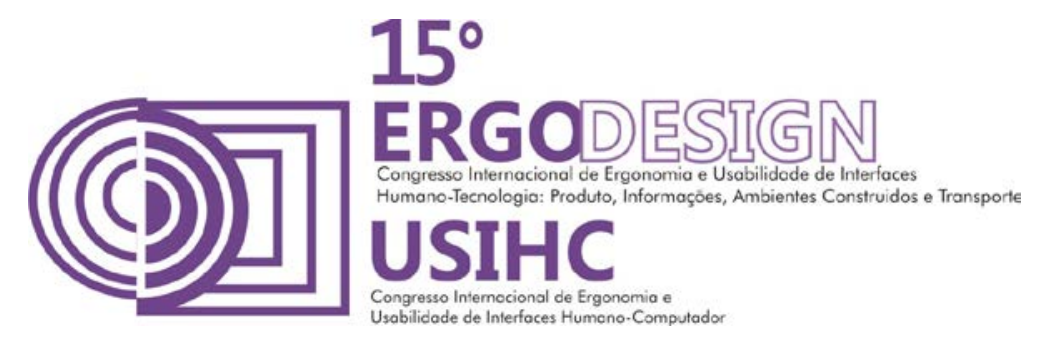

\begin{tabular}{|l|l|}
\hline $\begin{array}{l}\text { pessoas considerando } \\
\text { movimentação individual } \\
\text { ou coletiva: }\end{array}$ & \\
\hline $\begin{array}{l}\text { Evidências de níveis de } \\
\text { atenção ao entorno: }\end{array}$ & \\
\hline $\begin{array}{l}\text { Evidências de cuidado e } \\
\text { descuido com o lugar; }\end{array}$ & \\
\hline $\begin{array}{l}\text { Informações que as } \\
\text { pessoas procuram }\end{array}$ & \\
\hline $\begin{array}{l}\text { Sincronia entre fluxo de } \\
\text { entrada e saída: }\end{array}$ & \\
\hline
\end{tabular}

Figura 04 - Ficha de Observação Sistemática

As observações foram conduzidas com o apoio da ficha de observações que orientou o registro das informações.

\section{ANÁLISE E CATEGORIZAÇÃO DO COMPORTAMENTO DOS USUÁRIOS}

Registradas em ficha previamente preparada para cada visita, posteriormente as informações foram agrupadas considerando o critério de análise (origem do fluxo, comportamento das pessoas, informações procuradas entre outras) facilitando a percepção de padrões em determinados horários do dias. As informações que serão discutidas ao longo deste artigo são as observações relacionados a caracterização dos usuários, ao comportamento das pessoas, ao nível de atenção no ambiente, e, informações derivadas da experiência do observador no terminal urbano central.

\section{Observações relacionadas a caracterização dos usuários}

Alguns usuários usavam linguagem dos sinais evidenciando deficiência auditiva.

0 terminal é utilizado também por pessoas com mobilidade reduzida.

\section{Observações relacionadas ao Comportamento das pessoas}

Grande parte das pessoas utilizam do espaço fora da faixa de pedestre para cruzar o terminal, inclusive os trabalhadores da estação.

Os pedestres caminham ou correm pelo terminal livremente, de acordo com sua necessidade e dificilmente param de caminhar, só param em frente a plataforma de embarque ou formando grupos para conversar (mais comum entre jovens estudantes).

A velocidade da movimentação dos indivíduos podem variar de acordo com a necessidade da pessoa. Observou-se 6 padrões de níveis de velocidade de movimentação: marcha lenta, marcha semi-lenta, 


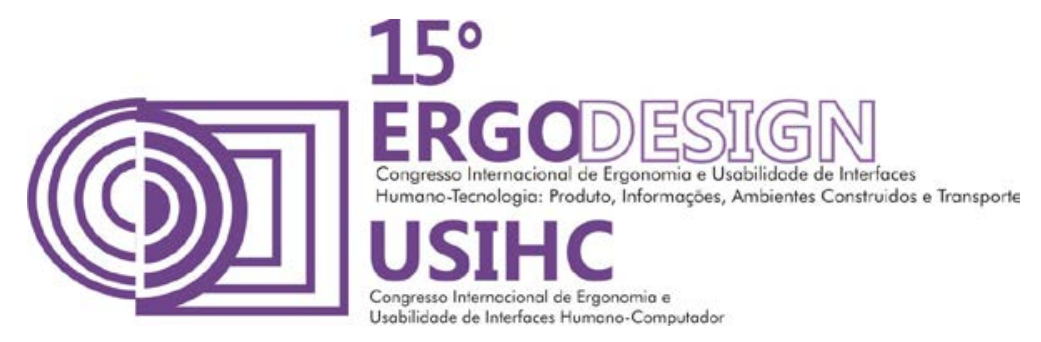

marcha normal, marcha rápida, corrida normal e corrida rápida.

Notou-se que as pessoas que andam lentamente, normalmente, utilizam o celular.

As pessoas que estão com pressa e andam rápido ou correm, consequentemente 'desobedecem' as orientações de sinalização.

Observou-se que a atividade mais frequente foi a movimentação, a segunda foi a comunicação (que pode ser feita pela linguagem falada, linguagem corporal ou por celulares e dispositivos) e a terceira foi 0 cuidado das pessoas com os pertences e consigo mesmo (os pertences mais comuns avistados foram mochilas, bolsas, sacolas, livros, comidas e celulares; estes, são carregados nas mãos ou estão pendurados no corpo).

A preocupação com os pertences ou com o próprio entorno pode ser desviada para o celular ou aparelho similar.

Quando a atenção for voltada ao pertence, pode parar a movimentação e/ou a comunicação.

As pessoas que andam acompanhadas ou em grupo no ambiente ficam normalmente a 1 metro de distância uma da outra.

Crianças estão frequentemente acompanhadas dos pais, passam por debaixo da catraca sem pagar 0 passe.

Aparentemente, as pessoas são mais gentis e pacientes de manhã (inclusive funcionários e motoristas) e se movimentam em um ritmo menos apressado neste período.

O clima (temperatura agradável, tempo claro) interfere no conforto e no comportamento dos usuários.

Em dias de calor há maior consumo de bebidas e sorvetes.

Aos sábados notou-se uma presença maior de sacolas associadas a compras.

Aos sábados percebeu-se uma maior quantidade de crianças acompanhadas dos pais.

Observações relacionadas ao nível de atenção

A atenção das pessoas se desvia dos pertences ou do próprio entorno, para o aparelho celular.

0 ruído é atenuado quando o fluxo de ônibus que diminuiu.

Para falar ao celular os usuários procuram privacidade em locais com menor circulação e acumulação de pessoas.

O fluxo de embarque/desembarque é desorganizado.

Observações que podem contribuir com a qualificação do sistema de orientação

Somente duas TVs informativas estão funcionando; em alguns dias elas estavam desligadas.

Não há informações que contribuam com a organização do fluxo de embarque/desembarque.

Entre os usuários observou-se pessoas com mobilidade reduzida e com deficiência auditiva.

Figura 05: observações sobre usuários, comportamento, nível de atenção no ambiente.

Ressalta-se que ao longo da pesquisa também foram registradas percepções derivadas da experiência de observação e do longo tempo que o autor foi exposto ao ambiente do terminal urbano. 


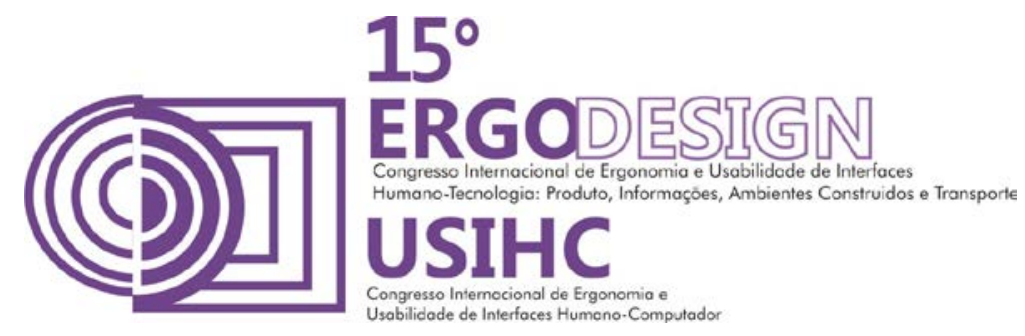

Observações derivadas da observação de experiência do observador no terminal urbano central

A locomoção pelo terminal em meio ao fluxo intenso de pessoas se locomovendo gerou desconforto e sentimentos semelhantes, como agonia, raiva, impaciência, etc.

A previsibilidade do aumento do fluxo de pessoas em horários de pico gerou desconforto.

O longo tempo de exposição ao ambiente gerou a sensação de insegurança.

Algumas das sensações como frio e calor estão associadas a exposição a condições climáticas mais intensas.

Ao longo da experiência percebeu-se odores desagradáveis derivados da movimentação de veículos e do consumo de produtos que as pessoas fazem no ambiente.

Figura 06: informações derivadas da experiência do observador.

\section{CONSIDERAÇÕES FINAIS E CONCLUSÕES}

A discussão dos resultados revelou possibilidades de intervenções e projetos futuros: (1) em relação a caracterização dos usuários notou-se a relevância em atender necessidades de pessoas com deficiência (físicas e de comunicação/sistema de orientação) e de variadas faixas etárias; (2) quanto ao comportamento das pessoas percebeu-se: a importância de sinalizar claramente áreas em que os pedestres podem transitar com segurança; a necessidade de adequar áreas de embarque/desembarque para aglomeração de pessoas; sinalizar qual o comportamento esperado considerando a velocidade de movimentação e os riscos associados a movimentação fora das áreas sinalizadas; oferecer informações amigáveis sobre os riscos associados a distrações derivadas do uso de aplicativos móveis (descuido com pertences, redução da atenção ao lugar atrapalhando o fluxo de pessoas); em áreas destinadas a aglomeração considerar que as pessoas preferem manter uma distância confortável umas das outras; avaliar a possibilidade de oferecer conforto térmico, reduzir o ruído e minimizar odores considerando que os mesmos afetam o comportamento do usuário; (3) em relação aos aspectos relacionados ao sistema de informações notou-se a insuficiência de equipamentos de TV com informações de interesse do usuário; percebeu-se também a necessidade de estruturar um sistema de organização do fluxo de embarque/desembarque; Além disso, projeto de um sistema de orientação deve atender também necessidades de pessoas com deficiência auditiva e/ou visual; (4) por fim, a partir da experiência do próprio observador notou-se: necessidade de organizar o fluxo e desenvolver um sistema eficiente de orientação; relevância de ampliar o conforto considerando temperatura, ruído e odores; aperfeiçoar aspectos relacionados a segurança. 


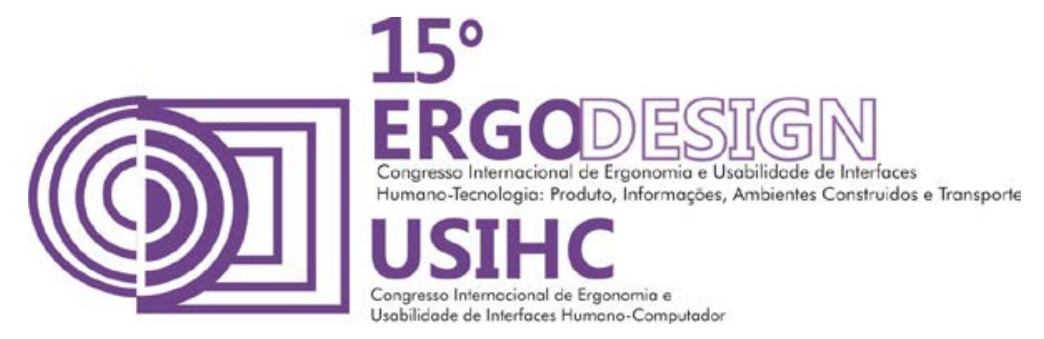

\section{REFERÊNCIAS BIBLIOGRÁFICAS}

IPPUJ. Joinville: Cidade em Dados 2010/2011. Disponível em http://www.ippuj.sc.gov.br/ conteudo.php?paginaCodigo=23. Acesso em: 23 de mai. 2013.

LERNER, Jaime. A Song of the City. Disponível em http://www.ted.com/talks/jaime lerner sings of the_city. Acesso em: 14 de mai. 2014.

MOGGRIDGE, Bill. Designing Interactions. Massachutsses Institute of Technology. 2007. Disponível em http://ellieharmon.com/wp-content/uploads/01-21-Moggridge-People.pdf.pdf. Acesso em: 7 de jan. 2015.

MORAES, Anamaria e MONT'ALVÃO, Claudia. Ergonomia - Conceitos e Aplicações. Rio de Janeiro : $2 A B, 2010$.

SANTA ROSA, José Guilherme. Ergodesign Participativo de Design de Interfaces tecnológicas: envolvendo o usuario no proceso de design ergonômico. In: PASCHOARELLI, Luiz Carlos, DA SILVA, José Carlos Plácido. Design Ergonômico, Estudos e Aplicações. Bauru : Canal 6, 2013. Pp. 5162.

REVISTA RODOVIAS \& VIAS. Os sistemas de metrô no mundo e a realidade das cidades brasileiras. Ed. 41, set-nov de 2009. Disponível em: <http://www2.rodoviasevias.com.br/ revista/materias. php?edicao $=$ Nacional41\&id $=419 \&$ codigo $=163 d 800710 / 2009>$. Acesso em: 15 de jul. 2010.

THACKARA, J. Plano B: o design e as alternativas viáveis em um mundo complexo. São Paulo: Saraiva: Versar, 2008. 